\title{
Induction of Spermatogenesis by Bone Marrow-derived Mesenchymal Stem Cells in Busulfan-induced Azoospermia in Hamster
}

\author{
Amin Tamadon ${ }^{1}$, Davood Mehrabani ${ }^{1}$, Farhad Rahmanifar ${ }^{2}$, Alireza Raayat Jahromi ${ }^{3}$, \\ Mohadeseh Panahi ${ }^{4}$, Shahrokh Zare ${ }^{1}$, Zahra Khodabandeh ${ }^{1}$, Iman Razeghian Jahromi ${ }^{1}$, \\ Nader Tanideh ${ }^{1,5}$, Mehdi Dianatpour ${ }^{1,6}$, Mani Ramzi ${ }^{7}$, Omid Koohi-Hoseinabadi ${ }^{8}$ \\ ${ }^{1}$ Stem Cell and Transgenic Technology Research Center, Shiraz University of Medical Sciences, Departments of ${ }^{2}$ Basic Sciences, \\ ${ }^{3}$ Clinical Sciences, ${ }^{4}$ DVM graduated, School of Veterinary Medicine, Shiraz University, Departments of ${ }^{5}$ Pharmacology, ${ }^{6}$ Human \\ Genetic, School of Medicine, Shiraz University of Medical Sciences, ${ }^{7}$ Hematology and Bone Marrow Transplant Research Center, \\ ${ }^{8}$ Laboratory Animal Center, Shiraz University of Medical Sciences, Shiraz, Iran
}

Background: Bone marrow-derived mesenchymal stem cells (BM-MSCs) have potential of differentiation and they secrete anti-inflammatory cytokines and growth factors which make them appropriate for cell therapy.

Aim of the Work: Were to evaluate the healing effect of BM-MSCs transplantation on germinal cells of busulfan-induced azoospermic hamsters.

Material and Methods: In the present experimental case control study, BM-MSCs were isolated from bone marrow of donor albino hamsters. Five mature male recipient hamsters received two doses of $10 \mathrm{mg} / \mathrm{kg}$ of busulfan with 21 days interval to stop endogenous spermatogenesis. After induction of azoospermia, right testis of hamsters was injected with $10^{6}$ BM-MSCs via efferent duct and the left one remained as azoospermia control testis. Five normal mature hamsters were selected as normal intact control. After 35 days, testes and epididymis of three groups were removed for histological evaluation.

Results: Histomorphological analyses of BM-MSCs treated testes and epididymis showed the epithelial tissue of seminiferous tubules had normal morphology and spermatozoa were present in epididymis tubes. Spermatogenesis was observed in most cell-treated seminiferous tubules. The untreated seminiferous tubules were empty.

Conclusion: Transplanted BM-MSCs could successfully induce spermatogenesis in seminiferous tubules of azoospermic hamster. Therefore, BM-MSCs can be an attractive candidate in cell transplantation of azoospermia.

Keywords: Bone marrow, Mesenchymal stem cell, Azoospermia, Cell therapy, Busulfan, Hamster

\footnotetext{
Accepted for publication October 2, 2015, Published online November 30, 2015 Correspondence to Davood Mehrabani

Stem Cell and Transgenic Technology Research Center, Shiraz University of Medical Sciences, Shiraz 71348-74478, Iran Tel/Fax: +98-71-3234-1025

E-mail:mehrabad@sums.ac.ir

(c) This is an open-access article distributed under the terms of the Creative Commons Attribution Non-Commercial License (http://creativecommons.org/ licenses/by-nc/4.0/), which permits unrestricted non-commercial use, distribution, and reproduction in any medium, provided the original work is properly cited.
}

\section{Introduction}

Approximately $1 \%$ of all men suffer from azoospermia in forms of obstructive or non-obstructive, and azoospermic men constitute approximately $10 \sim 15 \%$ of all infertile men (1). Much efforts were done to treat these infertile men, especially non-obstructive azoospermia, because their treatment is most difficult (2). In spite of hormonal or surgical treatments, in recent years, more attention has been centralized on the cell and stem cell therapy. Stem 
cell therapy has potential to develop more and being a choice for treatment of male infertility due to dysfunction of germ cells and their inability to differentiate or proliferate (3). This technique attracted significant interest for treatment of sperm deformity and azoospermia.

Moreover, stem cell therapy may help to reduce the effect of cancer therapeutics on reproductive failure in cancer patients. In addition, inter tubular injection of stem cells is used for production of transgenic mice (4) and rats (5). In-vitro previous studies showed germcell lineage can be differentiated from different kind of pluripotent stem cells including mesenchymal stem cells (MSCs) (6), including embryonic stem cells (ESCs) (7), induced pluripotent stem cells (8) and fetal stem cells (9). There are several reports on transplantation of MSCs to induce spermatogenesis in azoospermic models (10). They were isolated from different sources such as bone marrow (11), adipose tissue (12), endometrium (13), and dental pulp (14).

Lassalle et al. (15) injected BM-MSCs into testis to induce differentiation of these cells into germ cells but, they did not notice any differentiation. In another study in mouse and human, adult BM-MSCs grown in-vitro in the presence of retinoic acid were found to express germ cell markers, but there was still a failure to undergo spermatogenesis after transplantation into testes (16). Lue et al. (17) found different findings and showed that transplanting BM-MSCs into testis of a busulfan-treated infertile mouse model could differentiate into germ, sertoli and leydig cells. Cakici et al. (18) demonstrated that the treatment of busulfan-treated rat testes with adipose tissue derived MSCs resulted into morphologically normal spermatogenesis in some tubules after 12 weeks. Monsefi et al. (19) showed that transplanted BM-MSCs could differentiate into germinal cells in seminiferous tubules of Wistar rats. Although the possible mechanisms of healing are unclear, three mechanism might be responsible to recover testicular function during the tissue regeneration process by MSCs: (i) They may differentiate into the target cells via appropriate induction conditions (20); (ii) These cells secrete growth factors to stimulate the resident stem cells to restore the host cell function (21); and (iii) MSCs merged with the endogenous cells recover the injured tissue function (22). Therefore, this study was undertaken to use busulfan for induction of azoospermia and BM-MSCs for its cell therapy and further spermatogenesis in a hamster model.

\section{Materials and Methods}

\section{Animals}

Twelve albino male Syrian hamsters (Mesocricetus auratus) weighing 90 130 g were provided from Laboratory Animal Center, Shiraz University of Medical Sciences, Shiraz, Iran. They were housed in temperature-controlled rooms $\left(20 \sim 22^{\circ} \mathrm{C}\right)$ under $12 \mathrm{~h} \mathrm{light/dark} \mathrm{cycle.} \mathrm{The} \mathrm{ham-}$ sters were fed with standard commercial chow diet ad libitum. This project was approved by the Ethical Committee of Shiraz University of Medical Sciences (Shiraz, Iran). All efforts were made to minimize suffering during the experimental period.

\section{Isolation and culture of hamster BM-MSCs}

To isolate BM-MSCs, hamsters $(n=2)$ were anesthetized by ketamine (intraperitoneal injection, $100 \mathrm{mg} / \mathrm{kg}$, Woerden, Netherlands) and xylazine (intraperitoneal injection, 7 $\mathrm{mg} / \mathrm{kg}$, Alfazyne, Woerden, Netherlands) and then were euthanized by cervical dislocation. Incision was made on the skin and both femurs and humeruses and their muscular tissues were completely removed. After cutting the bones extremities, their bone marrows were washed and collected in falcon tube using a syringe full of Dulbecco's modified Eagles medium (DMEM; Gibco, USA) and 1\% penicillin and streptomycin (Sigma, USA).

The flushed marrow was centrifuged (5 min, $1500 \mathrm{rpm}$ ) and the supernatant was removed, and the pelleted fraction was resuspended in $5 \mathrm{ml}$ DMEM. The suspension were transferred into $25 \mathrm{ml}$ flasks containing DMEM, 10\% fetal bovine serum (FBS; USA), and 1\% penicillin and streptomycin. The flasks were in an incubator with 5\% $\mathrm{CO} 2$ at $37^{\circ} \mathrm{C}$ and saturated humidity. This initial passage of the primary cell culture was referred to as "Passage 0 ". Non-adherent cells with the medium were removed after $24 \mathrm{~h}$ and fresh medium was added again. The culture medium was changed every three days. When the cells reached $80 \sim 90 \%$ confluence, the cells were harvested using $0.25 \%$ trypsin (Gibco, USA), counted and passaged into new flasks.

To obtain a sufficient number of cells, they were sub-cultured two times using standard methods of trypsinization. Cells were collected in the third passage and were counted using a hemocytometer. They were kept in freezing media including 10\% dimethyl sulfoxide (DMSO; MP Bio, France) and $90 \%$ FBS, at a density of $2 \times 10^{6}$ viable cells $/ \mathrm{ml}$ and were aliquoted into sterile plastic cryovials that were labeled with the freezing serial number and the date. The vials were kept at $-20^{\circ} \mathrm{C}$ for $60 \mathrm{~min}$ and then they were transferred to $-70^{\circ} \mathrm{C}$ for $24 \mathrm{~h}$, and finally 
transferred to liquid nitrogen for long-term storage.

Before surgical treatment, the cryovials were removed from the liquid nitrogen and quickly thawed in a $37^{\circ} \mathrm{C}$ water bath. When the ice clump was almost thawed, $1 \mathrm{ml}$ of cell culture medium (89\% DMEM, 10\% FBS, and 1\% penicillin and streptomycin) was added, and centrifuged at $1500 \mathrm{rpm}$ for $5 \mathrm{~min}$. The BM-MSCs were transferred into a flask with gently blown into uniform single cell suspension, and cultured at $37^{\circ} \mathrm{C}$ and $5 \%$ CO2. All BM-MSCs were subcultured just up to passage 4 .

\section{Busulfan treatment of hamsters and BM-MSCs transplantation}

Five untreated male hamsters served as negative control and 5 male hamsters were used as a model of inducing azoospermia by injection of two dose of busulfan $(10 \mathrm{mg} / \mathrm{kg}$ body weight, intraperitoneally, Busilvex ${ }^{\circledR}$, Pierre Fabre
Medicament, Boulogne, France) with 21 days interval. Thirty five days after the last busulfan injection, male hamsters were anaesthetized by ketamine and xylazine. Their abdominal area was surgically prepared in dorsal recumbency and $1 \mathrm{~cm}$ midline abdominal incision was made to expose the peritoneal cavity.

Under a stereomicroscope (Model SZN, Optika, Italy), the fat pad attached to the right epididymis and testis was gently pulled using an iris forceps. The testis was exteriorized and the testicular artery and epididymis were clearly visible. A thin sterile black plastic card with a 30 degree V-like cut was put underneath the testis as a holder. Suspension of BM-MSCs was mixed with sterile trypan blue $(1: 1, \mathrm{v} / \mathrm{v})$ and was loaded into the polyethylene tube connected to a $1 \mathrm{ml}$ syringe (Fig. 1A). A pulled pipette was attached into the tube. By applying pressure to the syringe, the cell suspension was gently forced into the
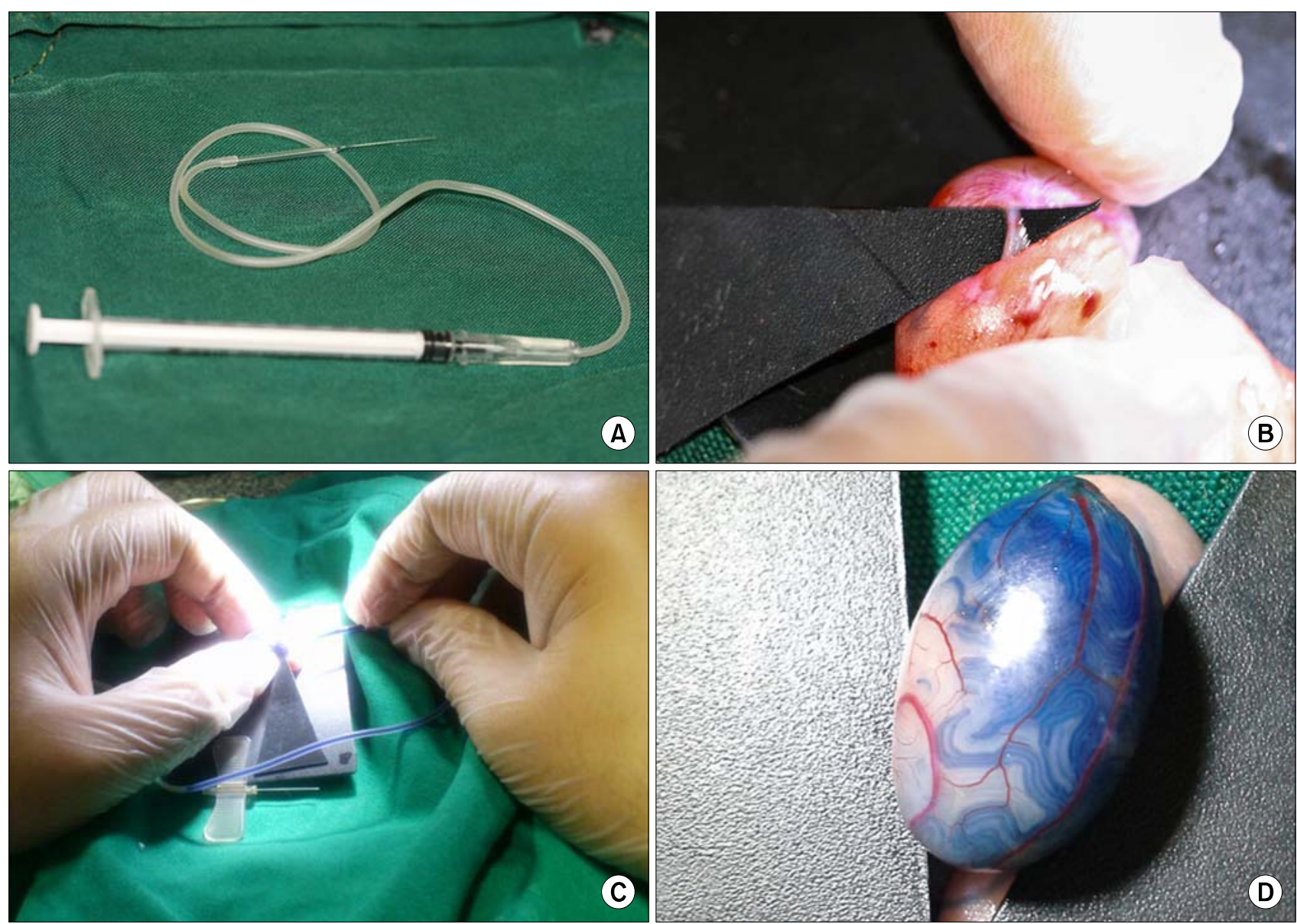

Fig. 1. (A) Designed micro-injector consistent of a $1 \mathrm{~mL}$ syringe (without needle), tube of a 24 gage butterfly needle, and a pre-pulled glass pipette. (B) To make a good contrast between the translucent efferent duct and the fat tissue and the membrane around it, a triangular hard black plastic card was inserted underneath the duct. (C) Bone marrow-derived mesenchymal stem cells (BM-MSCs) transplantation $\left(10^{6}\right.$ cells were mixed with trypan blue) into efferent duct of hamster testis. (D) Seminiferous tubules were filled with mixture of BM-MSCs and die. 
pipette.

The efferent duct that connects the testis to the epididymis was identified and fat tissue was gently removed around the ducts using a sharp needle. To make a good contrast between the translucent duct and the fat tissue and membrane around it, a triangular hard black plastic card was inserted underneath the duct (Fig. 1B). The pipette was carefully inserted into a duct in the bundle of efferent duct and gently threaded a few $\mathrm{mm}$ toward the testis (Fig. 1C). While avoiding moving the injection pipette, the plunger of the syringe was gently depressed and the blue suspension flowed into the rete testis. Then, almost all surface seminiferous tubules were filled with suspension (Fig. 1D). BM-MSCs' mixture (10 cells in $100 \mu \mathrm{L})$ was completely injected. The testis was returned to the abdominal cavity and the abdominal wall and the skin were sutured. The untreated left testis was served as positive control.

\section{BM-MSCs osteogenic and adipogenic differentiations}

For in-vitro osteogenic differentiation, cells at $90 \%$ confluence were cultivated in DMEM, 15\% FBS, $200 \mu \mathrm{M}$ L-ascorbic acid, $10 \mathrm{mM}$ glycerolphosphate, and $100 \mathrm{nM}$ dexamethasone. The medium was changed twice a week for 3 weeks. After 21 days, osteogenic differentiation was evaluated using Alzarin red staining. In brief, BM-MSCs cultures were fixed with $4 \%$ paraformaldehyde for 10 minutes. Then cells were incubated for 20 minutes at room temperature in 1\% Alizarin red and 1\% ammonium hydroxide. Following incubation, cultures were washed 4 times, 5 minute each time with $1 \mathrm{ml} \mathrm{dH_{2 }} \mathrm{O}$ replacing the water at each 5 minute interval and air-dried. Alizarin red dye binds to calcium ions present in mineralized deposits resulting in a brilliant red staining (all reagents from Sigma-Aldrich, USA).

For adipogenic differentiation, cells at $90 \%$ confluence were cultivated in DMEM, 15\% FBS, $0.2 \mathrm{mM}$ L-glutamine, $100 \mu \mathrm{M}$ L-ascorbic acid, $200 \mu \mathrm{M}$ indomethacin, and $100 \mathrm{nM}$ dexamethasone. The medium was changed twice a week for 3 weeks. After 21 days, adipogenic differentiation was evaluated using Oil Red $\mathrm{O}$ staining. In brief, for evaluating the generation of oil droplets, the BM-MSCs were fixed in $10 \%$ formalin for $10 \mathrm{~min}$ at room temperature and washed twice with water. Oil red $\mathrm{O}$ working solution was prepared by adding $6 \mathrm{~mL}$ of stock solution $(0.5$ $\mathrm{g}$ oil red in $100 \mathrm{~mL}$ isopropanol) to $4 \mathrm{~mL}$ distilled water, mixed, and filtered through Whatman filter paper. Next, oil red $\mathrm{O}$ stain was added and incubated for $1 \mathrm{~h}$ at room temperature. Finally, the cells were rinsed several times with water and observed under an inverted microscope (all reagents from Sigma-Aldrich, USA).

\section{Characterization of BM-MSCs by reverse transcription polymerase chain reaction (RT-PCR)}

To quantify the expression of BM-MSCs specific markers (CD29 and CD73) and absence of hematopoietic stem cells specific marker (CD45), RT-PCR was performed. First of all, total RNA was extracted using the Column RNA Isolation Kit (Denazist-Asia, Iran) in accordance with the manufacturer's instructions. Total RNA concentration was evaluated by spectrophotometer. After that, complementary DNA (cDNA) synthesis from RNA samples was done by using AccuPower Cycle Script RT PreMix Kit (Bioneer, Korea) according to the manufacturer's instructions.

Briefly, $15 \mu \mathrm{L}$ of total RNA was used for each reaction and the volume had been reached up to $20 \mu \mathrm{L}$ with the DEPC water. Twelve thermal cycles was performed with the following way: $30 \mathrm{sec}$ at $20^{\circ} \mathrm{C}$ for primer annealing, $4 \mathrm{~min}$ at $42^{\circ} \mathrm{C}$ for cDNA synthesis, $30 \mathrm{sec}$ at $55^{\circ} \mathrm{C}$ for melting secondary structure and cDNA synthesis and $5 \mathrm{mi}-$ nutes at $95^{\circ} \mathrm{C}$ in order to heat inactivation. In the third step, $1 \mu \mathrm{L}$ of template (cDNA) was mixed with other reagents consisting of PCR buffer, $\mathrm{MgCl}_{2}, \mathrm{H}_{2} \mathrm{O}$, dNTPs, Taq DNA polymerase, forward and reverse primers (CD29, CD73, and CD45) (Table 1). Then, microfuge tubes containing of $20 \mu \mathrm{L}$ above mixing were put in Thermocycler (Eppendorf Mastercycler Gradient, Eppendorf, Hamburg,

Table 1. Sequences of RT-PCR primers used to quantify the expression of bone marrow-derived mesenchymal stem cells specific markers (CD29 and CD73) and hematopoietic stem cells specific markers (CD45) in hamster

\begin{tabular}{llc}
\hline Primer & \multicolumn{1}{c}{ Primer sequence } & Amplicon length (bp) \\
\hline CD29-F & CAGTGAATAGCAACAATGAAGC & 133 \\
CD29-R & ATAAGCAGCAAGGCAAGG & 257 \\
CD73-F & TGGGAGGGAGAAGAGGATGGC & \\
CD73-R & GGAGAGTGGCAGGCAGAAATAAACC & 265 \\
CD45-F & TGATGCTATGCTGGAAGG & \\
CD45-R & GTATGAAGGAAGTCTCTGGAA & \\
\hline
\end{tabular}


Germany). Thirty amplification cycles were run, consisting of $30 \mathrm{sec}$ denaturation at $95^{\circ} \mathrm{C}, 30 \mathrm{sec}$ annealing at $64^{\circ} \mathrm{C}$ and $30 \mathrm{sec}$ extension at $72^{\circ} \mathrm{C}$ with the $2 \mathrm{~min}$ at $95^{\circ} \mathrm{C}$ for primary denaturation and $5 \mathrm{~min}$ at $72^{\circ} \mathrm{C}$ for final extension. PCR products were evaluated for the presence of considered bands by gel electrophoresis with the aid of DNA safe stain in $1.5 \%$ agarose gel medium. Produced bands were visualized under UV radiation by Gel documentation system (UVtec, Cambridge, UK).

\section{Histomorphometric analysis of testes}

Thirty five days after cell injection, animals were euthanized with ether and their testes and epididymis tails were collected and fixed in a 10\% formalin buffer solution. After fixation, segments were embedded in paraffin, and histological sections were made from each block. The 5 $\mu \mathrm{m}$ thickness hematoxylin-eosin stained sections were examined under light microscope for any spermatogenic activity.

For each testis five vertical sections from the polar and the equatorial regions were sampled. In one cross-section per animal, all tubules were evaluated for presence of spermatogonia, spermatocytes and spermatids. In 10 circular transverse sections of tubules, each from a different region of the testis and each homogeneous throughout with respect to cell associations and spermiogenesis, we measured inner, outer and total diameters, calculated areas of the cellular and luminal regions and cross sectional area of the tubule, and counted the number of late spermatids present.

The mean seminiferous tubule diameter (D) was de- rived by taking the average of two diameters, D1 and D2 at right angles. Cross-sectional area (Ac) of the seminiferous tubules was determined using the equation $\mathrm{Ac}=$ $\pi \mathrm{D} 2 / 4$, where $\pi$ is equivalent to 3.142 and $\mathrm{D}$ the mean diameter of seminiferous tubules (23). A testis was rated for its spermatogenic potential (modified spermatogenic index) on a modified scale of 0 to 5 (23). The index was based on the appearance of the spermatogenic cells throughout the testis and included number of cell layers, types of cells, and the presence of late spermatids in the seminiferous tubules. The index and criteria were as follows: 0 , no spermatogenic cells; 1 , only spermatogonia present; 2, spermatogonia and spermatocytes present; 3, spermatogonia, spermatocytes and round (early) spermatids present with $<50$ late spermatids per tubule; 4, spermatogonia, spermatocytes, and round spermatids present; and up to $50 \sim 100$ late spermatids per tubule; and 5, all cell types present and $>100$ late spermatids per tubule.

\section{Statistical analysis}

Means and standard error (SE) of the data of histomorphometric indices of seminiferous tubules were subjected to Kolmogorov-Smirnov test of normality and analyzed by one-way ANOVA (SPSS for Windows, version 11.5, SPSS Inc, Chicago, Illinois), and post-hoc test was performed by Tukey test. The spermatogenesis index of seminiferous tubules was compared using Mann-Whitney $\mathrm{U}$ test. The $\mathrm{p}$ value of less than 0.05 was considered to be statistically significant. Group means and their standard error were reported in the text and graphs (GraphPad Prism version 5.01 for Windows, GraphPad software Inc.,
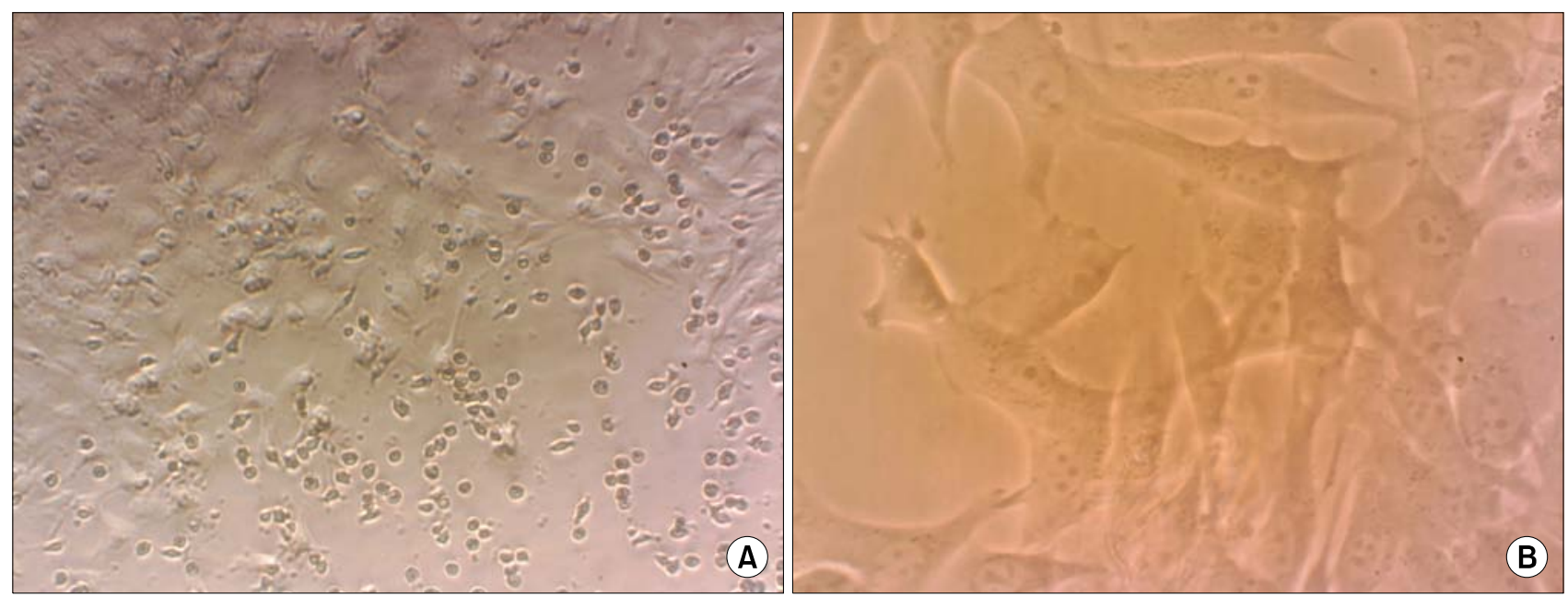

Fig. 2. Morphological and phenotypic characteristics of hamster bone marrow mesenchymal stem cells. (A) At passage 0 , earlier stage. Diverse morphologies including attached spindle-shaped and flattened cells and round other bone marrow cells. (B) Stem cells exhibited large, flattened or fibroblast-like morphology in passage 3. 

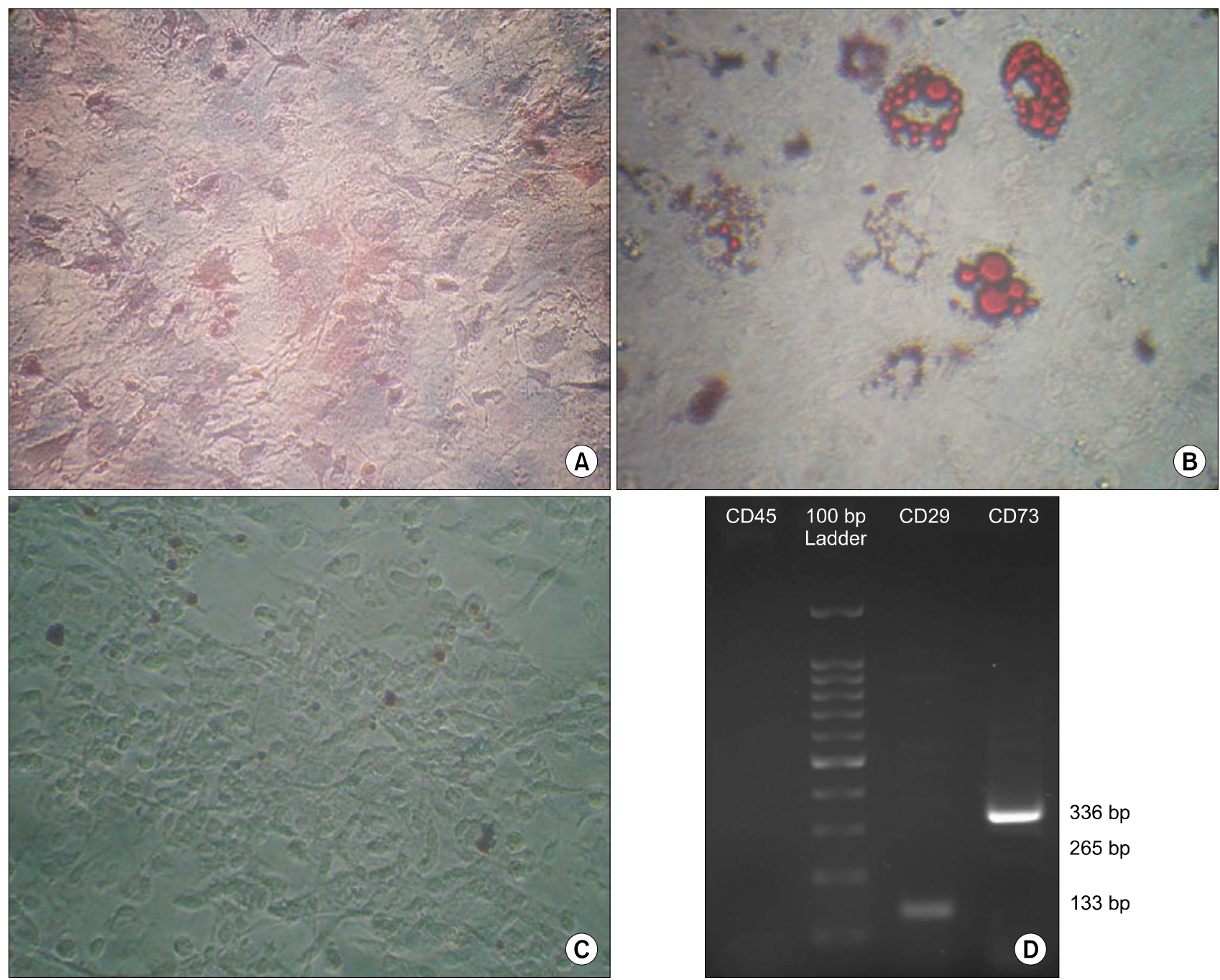

Fig. 3. Bone marrow-derived mesenchymal stem cells of hamster cultivated in (A) osteogenic medium and stained with Alizarin Red ( $\times 100)$, (B) in adipogenic medium and were stained with Oil Red $\mathrm{O}$ at day 21 after induction $(\times 200)$, and $(C)$ in culture media without differentiation medium as control $(\times 100)$. (D) Activation of specific mesenchymal marker (CD29 and CD73) compared with deactivation of specific hematopoietic marker (CD45) of hamster bone marrow-derived stem cells.

San Diego, CA, USA).

\section{Results}

\section{Culture of BM-MSC}

BM-MSCs showed a fibroblast-like, spindle-shaped morphology after they attached to the culture flasks. BM-MSCs proliferation started $3 \sim 4$ days after incubation until reaching an $80 \%$ confluence (Fig. 2).

\section{BM-MSCs osteogenic and adipogenic differentiations}

To further confirm the differentiation capacity of BM-MSCs, osteogenic and adipogenic differentiations were induced. After culture of BM-MSCs in osteogenic differ- entiation medium, the cells differentiated toward osteoblasts as verified by positive staining with Alzarin Red staining (Fig. 3A). BM-MSCs treated by the adipogenic differentiation protocol showed the presence of intracellular lipid droplets, which were confirmed by Oil Red $\mathrm{O}$ staining (Fig. 3B). The BM-MSCs grown in culture medium alone (undifferentiation) did not show any osteoblast characters or lipid droplets at any of the time points examined, and maintained their typical fibroblast-like shape (Fig. 3C).

\section{Characterization by RT-PCR}

According to proof of the mesenchymal property of hamster BM-MSCs, these cells were expanded up to pas- 
sage 3 and then they were analyzed using a RT-PCR assay. Fig. 3D displays positive expression for CD29 and CD73 (mesenchymal cell marker) and negative expression for CD45 (hematopoietic cell marker).

\section{Histological assessment of spermatogenesis}

After induction the azoospermia in the hamsters with double injection of $10 \mathrm{mg} / \mathrm{kg}$ of busulfan, the testes of the control hamsters were microscopically examined for any spontaneous spermatogenesis recovery and no sign was
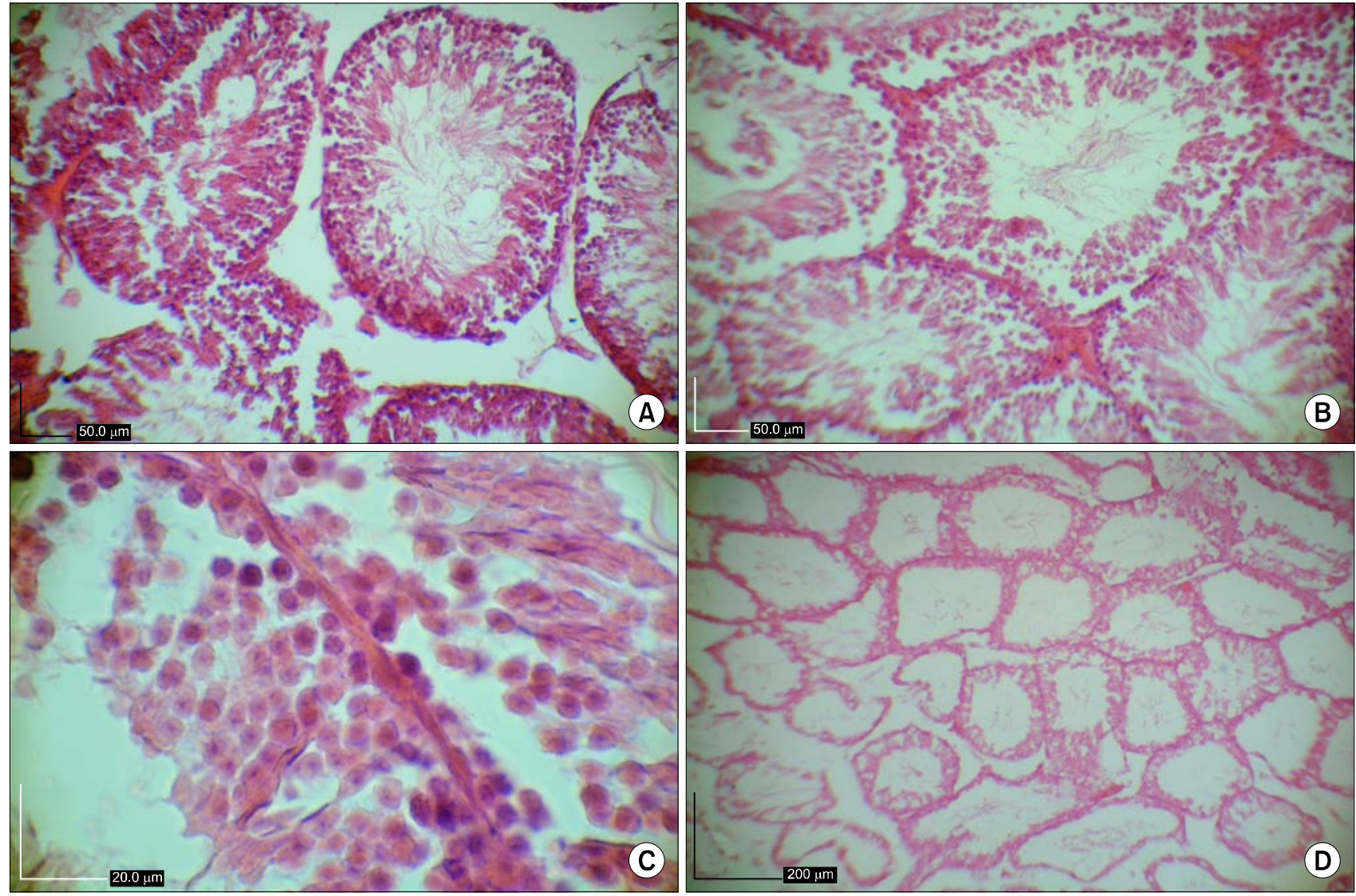

Fig. 4. (A) Sections of seminiferous tubules of normal control hamster. Tubules have condensed spermatogenic epithelium. (B) Sections of seminiferous tubules of treated hamster with bone marrow mesenchymal stem cells. Most of tubules appeared to be filled up with spermatogenic cells. (C) Presence of different kind of germinal epithelial cells in stem cell treated seminiferous tubules. (D) Busulfan treated azoospermic control seminiferous tubules. The seminiferous tubules were partially empty and without vacuolated germinal layer cells indicating the absence of spermatogenesis. Hematoxylin and eosin staining.
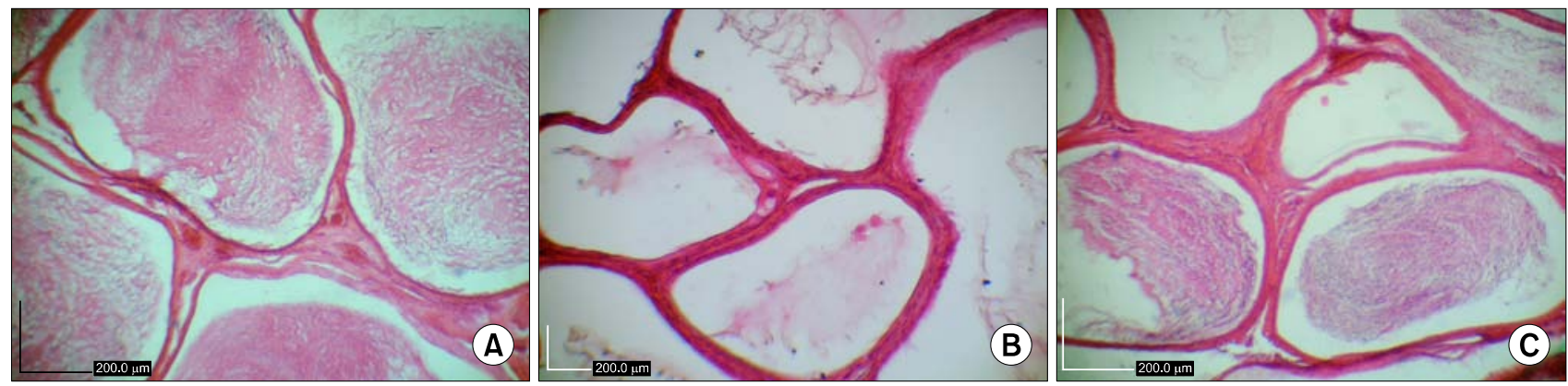

Fig. 5. Sections of epididymis tubules of (A) normal control, (B) busulfan treated azoospermic control, and (C) bone marrow mesenchymal stem cells treated hamsters. Hematoxylin and eosin staining. 
observed. After the treatment with busulfan, the seminiferous tubules of the testes were not treated with BM-MSCs were empty and their spermatogenesis process was disrupted (Fig. 4D). The examination of sections showed only sertoli cell appearance for samples without BM-MSCs therapy.
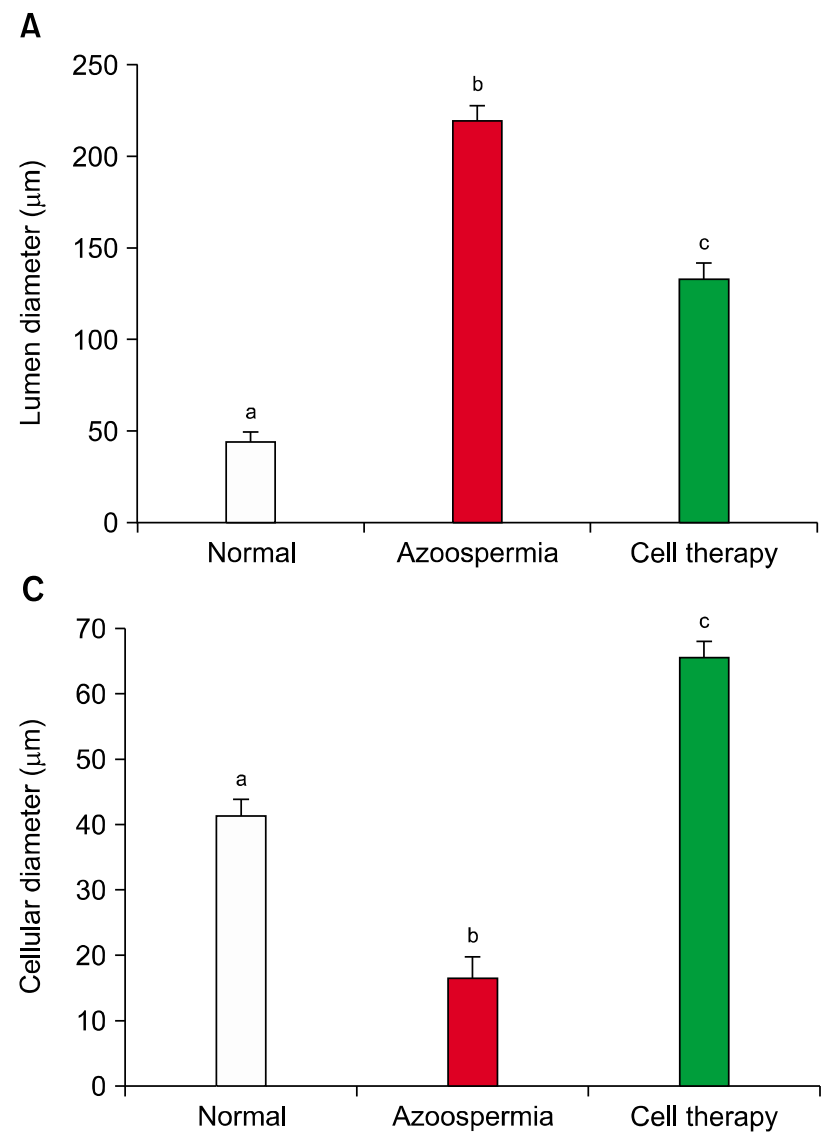

E

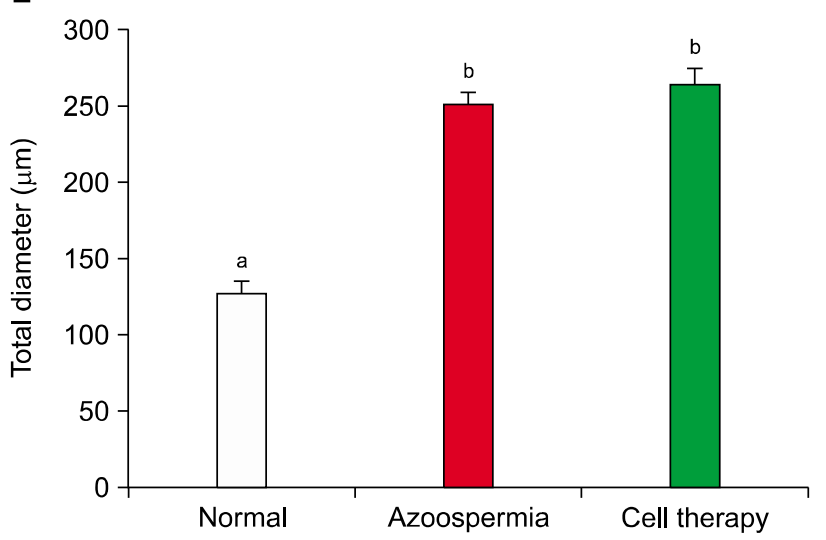

Histological examinations of testes in busulfan treatment group after two months revealed some degenerative changes such as seminiferous tubular atrophy and germinal epitheliums degenerations in the most of tubules. The large vacuolated lumen occupied seminiferous tubules and the atrophic germinal epithelium covered peripheral zone

B
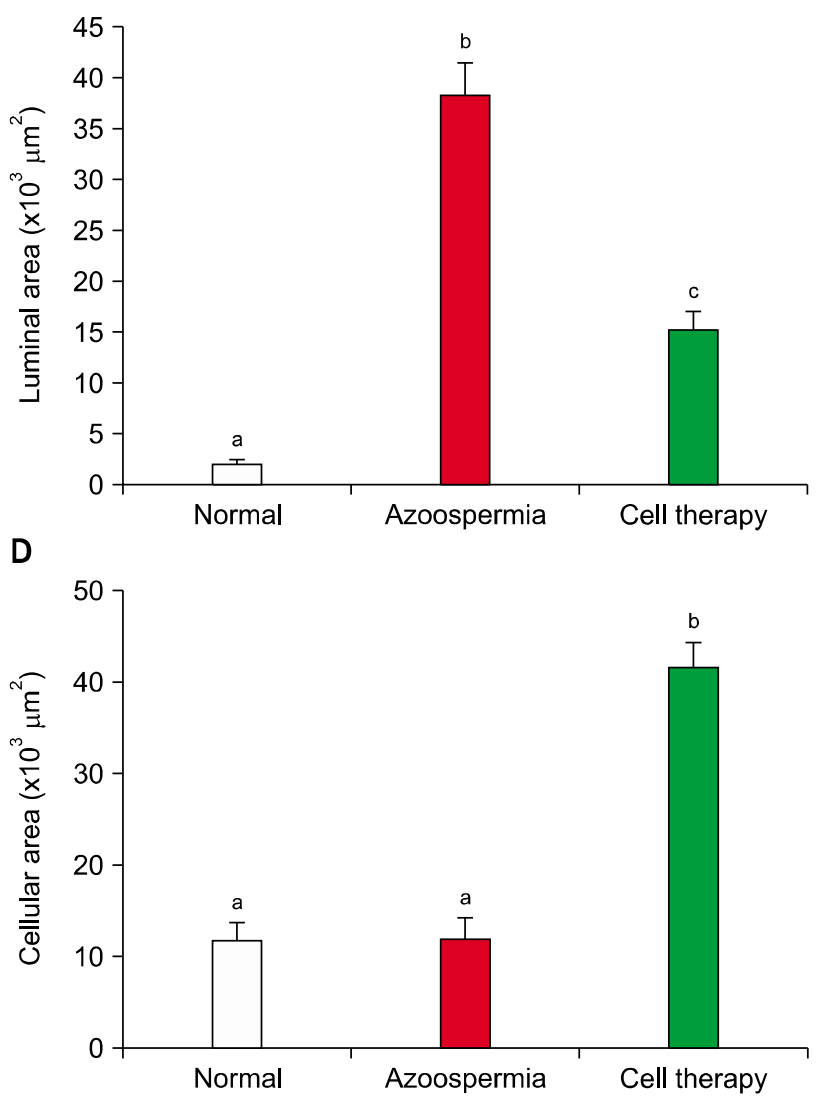

$\mathrm{F}$

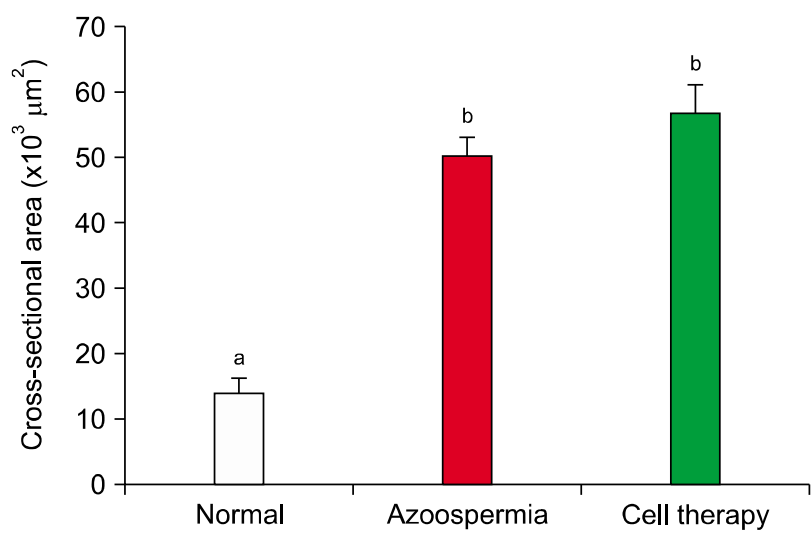

Fig. 6. Mean and standard error of histomorphometric indices of seminiferous tubules in busulfan-induced azoospermic testis treated with bone marrow mesenchymal stem cells (cell therapy) in comparison with busulfan treated testes (azoospermia) and intact normal testis (normal) in hamster. (A) Lumen diameter $(\mu \mathrm{m})$, (B) Luminal area $\left(\mu \mathrm{m}^{2}\right)$, (C) Cellular diameter $(\mu \mathrm{m})$, (D) Cellular area $\left(\mu \mathrm{m}^{2}\right)$, (E) Total diameters $(\mu \mathrm{m})$, and $(\mathrm{F})$ Cross sectional area of the tubule $\left(\mu \mathrm{m}^{2}\right)$. ${ }^{\mathrm{a}, \mathrm{b}, \mathrm{c}}$ different superscript letters show significant differences between groups $(\mathrm{p}<0.05)$. 
of seminiferous tubules as thin band. Moreover, there were no spermatozoa in the epididymis of busulfan treated azoospermic group (Fig. 5B).

However, the presence of spermatogonia in the seminiferous tubules with BM-MSCs transplantation was observed (Fig. 4B). Moreover, the tubules appeared to be filled up with germinal cells (spermatogonia, primary spermatocytes, spermatids and sperms) in the sections of BM-MSCs-treated testis (Fig. 4C). Most of the epididymis tubes of cell treated groups have spermatozoa, but there was some tubes were empty (Fig. 5C). In comparison with treated group, normal intact hamsters had more condensed germinal epithelium (Fig. 4A) and all of epididymis tubes were filled by spermatozoa (Fig. 5A).

Histomorphometric measurements indicated the lumen diameter and luminal area of the seminiferous tubules in hamsters with stem cell transplantation were less than the azoospermic hamsters $(\mathrm{p}=0.001$ and $\mathrm{p}=0.001$, respectively) and more than normal hamster $(p=0.001$ and $p=0.001$, respectively; Figs. 6A and 6B). Cellular diameter and cellular area of the seminiferous tubules in hamsters with stem cell transplantation were more than azoospermic and normal control groups $(\mathrm{p}=0.001$ and $\mathrm{p}=0.001$, respectively; Figs. 6B and 6C). However, cellular diameter of normal control group was more than azoospermic hamsters $(p=0.001)$, but cellular area of these two groups were not different $(\mathrm{p}=1.0)$.

Total diameter and cross sectional area of the semi-

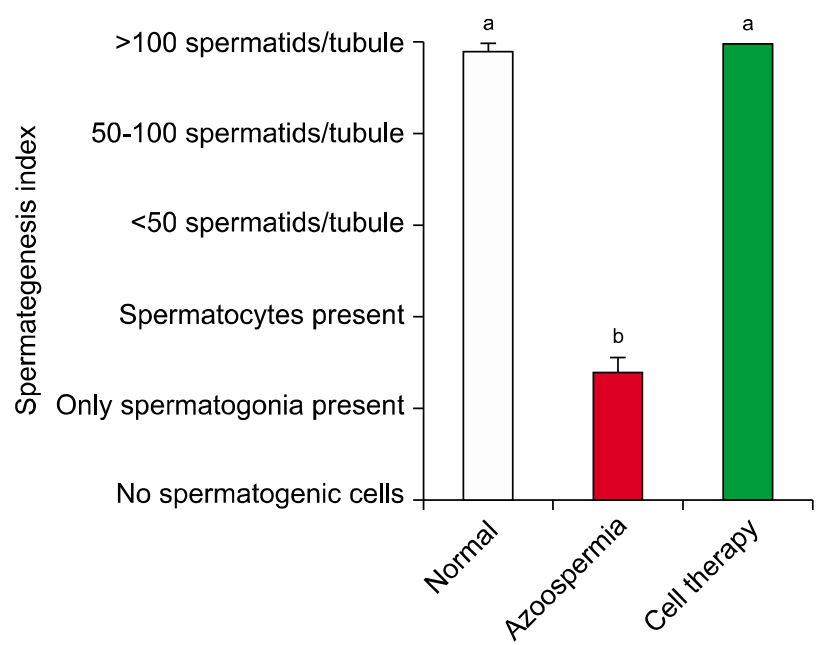

Fig. 7. Mean and standard error of spermatogenesis index of seminiferous tubules in busulfan-induced azoospermic testis treated with bone marrow mesenchymal stem cells (cell therapy) in comparison with busulfan treated testes (azoospermia) and intact normal testis (normal) in hamster. ${ }^{\mathrm{a}, \mathrm{b}}$ different superscript letters show significant differences between groups $(p<0.05)$. niferous tubules in hamsters with stem cell transplantation were not different with azoospermic hamsters $(\mathrm{p}=0.7$ and $p=0.5$, respectively; Figs. $6 \mathrm{D}$ and $6 \mathrm{E}$ ) but both groups were more than the normal control $(p=0.001, p=0.001$, $\mathrm{p}=0.001$ and $\mathrm{p}=0.001$, respectively).

Spermatogenesis index of seminiferous tubules in hamsters with stem cell transplantation did not have difference with normal control hamsters $(p=0.7)$, but both groups were more than the positive control hamsters $(p=0.001$ and $p=0.001$, respectively; Fig. 7).

\section{Discussion}

In the present study, BM-MSCs interactions in the hamster testis were evaluated functionally by transplantation of busulfan-induced azoospermic hamster testis. Injected BM-MSCs induced spermatogenesis. However, the damaged somatic environment of the testis is one of the most problem and limiting step in this method of infertility treatment. Damaged testis is not receptive to spermatogonial stem cells transplantation and thereby not able to treat patient azoospermia (24). Interestingly, BM-MSCs are not only hypo-immunogenic but also produce immunosurveillance or immunosuppression upon transplantation, therefore they are suitable for allogeneic transplantation (25). Intravenously bone BM-MSCs transfusion showed immunomodulatory effects on antisperm antibody production in allogeneic settings in mice after testis rupture (26). Moreover, sertoli cells are immune tolerant cells (27) and they can cause survival of the donor BM-MSCs and protect the transplanted allogeneic cells from post transplantation immune or inflammatory reaction.

In the present study, spermatogenesis index of seminiferous tubules in hamsters with stem cell transplantation did not have difference with normal control hamsters. Seminiferous tubules provide cyclic and dynamic regulation of spermatogenesis, and sertoli cells prepare a microenvironment that induces spermatogonial proliferation and differentiation. Our results also showed that BM-MSCs can induce reconstitution of the tubular microenvironment which helps remained inactivated germinal cells to proliferate in the host seminiferous tubules.

In some studies combination of in-vitro differentiation and in-vivo transplantation was performed to obtain advanced differentiated spermatozoa (28). Several in-vivo studies have been performed to evaluate the differentiation potential of mesenchymal stem cells into spermatozoa in rat and mice animal models. However, Van Saen et al. (29) and Lassalle et al. (15) showed that BM-MSCs could not differentiate into sperm in mice, but in the oth- 
er study, transplanted mouse BM-MSCs have been demonstrated to form germ cells in-vivo (17). Moreover, BM-MSCs was differentiation into germ cells and spermatozoa in-vitro (30). Nayernia et al. (16) demonstrated that murine BM-MSCs are able to differentiate into early germ cells in-vitro and in-vivo in mice.

Allogeneic BM-MSCs trans-differentiated into spermatogenic-like-cells and enhanced endogenous fertility recovery in rat by injection into seminiferous tubules of recipient with busulfan induced $(2,19,31)$ and testicular torsion (32) azoospermia rat. Mehrabani et al. (33) and Cakici et al. (18) demonstrated that adipose-tissue-derived MSCs can leading to recovery of fertility in the busulfan-treated azoospermia rat model. Recently, Chen et al. (34) showed that sperm differentiation potential of transplantation of human umbilical cord MSCs into immunodeficient mouse seminiferous tubule. Therefore, success in MSCs therapy of azoospermia in animal models may be species dependent.

Various conditions can cause non-obstructive azoospermia, including congenital or genetic abnormalities, exposure to gonadotoxins, infectious issues, varicocele, trauma, medications such as chemotherapy reagents, endocrine disorders, and idiopathic causes. Current medical therapy, including hormone or surgical methods, shows little benefit to non-obstructive azoospermia (35). Busulfan is a chemotherapeutic agent that most often use as low dose in a long time manner to treat chronic myeloid leukaemia (36). Before allogeneic transplantation of hematopoietic cell, busulfan is used as a myeloablative agent (37). Despite of its beneficial effects, cells with high division activities such as germ cells are more susceptible to busulfan side effects.

Spermatogonial stem cells of different species can be destroyed by busulfan $(23,38)$. But it has no effects on DNA synthesis. However, when busulfan intoxicates the cells in the Gl phase, inhibits the next mitosis (39). Busulfan-treated hamsters are excellent and well-established recipients for evaluating stem cell activity in hamster testis cell populations (38). They were used as recipients in this study.

On the other hand, morphometric findings of the present study showed a new feature of azoospermia cell therapies. Total diameter and cross sectional area of the seminiferous tubules in hamsters before and after transplantation were more than the normal control. Moreover, the lumen diameter and luminal area of the seminiferous tubules in hamsters with stem cell transplantation were more than the azoospermic hamsters and less than normal hamster. These morphostructural change can be explained that after induction of azoospermia some tubes collapsed and even after cell therapy, the tubular structures of semi- niferous which were treated in BM-MSC treated groups and untreated ones in azoospermia groups had more space to grown by the intratubular hydrostatic pressure of fluid and cell grown.

The intratubular hydrostatic pressure of hamster seminiferous tubules are $2 \sim 3 \mathrm{~mm} \mathrm{Hg}$ (40). Increase of total diameter may reduce the contraction ability of peritubular layer of contractile myofibroblast cells which may resulted in observed decrease of spermatozoa in epididymis of BM-MSCs treated hamsters. In addition, cellular diameter and cellular area of the seminiferous tubules in hamsters with stem cell transplantation were more than azoospermic and normal control groups. These were caused by increasing total diameter of treated animals' seminiferous tubules and increase of space between sertoli cells resulted in more places for cell proliferation.

Interestingly, however, cellular diameter of normal control group was more than azoospermic hamsters, but cellular area of those two groups were not different. Increase of cross sectional area of tubules in azoospermic hamster and moreover, greater space for non-busulfan affected Sertoli cells helps the cells to cover a more two-dimensional area than a normal groups.

\section{Conclusion}

Cell therapy could help the fast repair of pathological changes in testicular seminiferous tubules. It seems BMMSCs were found effective in treating animal model of azoospermia. The fertile status of busulfan induced azoospermic hamsters was recovered by transplantation of BM-MSCs. This finding raises the possibility of using BM-MSCs to treat azoospermia in human. But, more similar studies are need in different animal models to approve using of this technique in treatment of azoospermia and infertility in human.

\section{Acknowledgments}

The authors would like to appreciate the kind of Stem Cell and Transgenic Technology Research Center for laboratory cooperation. This study was funded by a grant from the Shiraz University, DVM thesis and Stem Cell and Transgenic Technology Research Center, Shiraz University of Medical Sciences.

\section{Potential conflict of interest}

There is no conflict of interest. 


\section{References}

1. Gudeloglu A, Parekattil SJ. Update in the evaluation of the azoospermic male. Clinics (Sao Paulo) 2013;68 Suppl 1:27-34

2. Zhang D, Liu X, Peng J, He D, Lin T, Zhu J, Li X, Zhang Y, Wei G. Potential spermatogenesis recovery with bone marrow mesenchymal stem cells in an azoospermic rat model. Int J Mol Sci 2014;15:13151-13165

3. O'Flynn O'Brien KL, Varghese AC, Agarwal A. The genetic causes of male factor infertility: a review. Fertil Steril 2010;93:1-12

4. Honaramooz A, Megee S, Zeng W, Destrempes MM, Overton SA, Luo J, Galantino-Homer H, Modelski M, Chen F, Blash S, Melican DT, Gavin WG, Ayres S, Yang F, Wang PJ, Echelard Y, Dobrinski I. Adeno-associated virus (AAV)-mediated transduction of male germ line stem cells results in transgene transmission after germ cell transplantation. FASEB J 2008;22:374-382

5. Ryu BY, Orwig KE, Oatley JM, Lin CC, Chang LJ, Avarbock MR, Brinster RL. Efficient generation of transgenic rats through the male germline using lentiviral transduction and transplantation of spermatogonial stem cells. J Androl 2007;28:353-360

6. Danner S, Kajahn J, Geismann C, Klink E, Kruse C. Derivation of oocyte-like cells from a clonal pancreatic stem cell line. Mol Hum Reprod 2007;13:11-20

7. Bucay N, Yebra M, Cirulli V, Afrikanova I, Kaido T, Hayek A, Montgomery AM. A novel approach for the derivation of putative primordial germ cells and sertoli cells from human embryonic stem cells. Stem Cells 2009;27:68-77

8. Yang S, Bo J, Hu H, Guo X, Tian R, Sun C, Zhu Y, Li P, Liu P, Zou S, Huang Y, Li Z. Derivation of male germ cells from induced pluripotent stem cells in vitro and in reconstituted seminiferous tubules. Cell Prolif 2012;45: 91-100

9. Dyce PW, Wen L, Li J. In vitro germline potential of stem cells derived from fetal porcine skin. Nat Cell Biol 2006; 8:384-390

10. Moreno I, Míguez-Forjan JM, Simón C. Artificial gametes from stem cells. Clin Exp Reprod Med 2015;42:33-44

11. Asadi-Yousefabad SL, Khodakaram-Tafti A, Dianatpour M, Mehrabani D, Zare S, Tamadon A, Nikeghbalian S, RaayatJahromi A, Ahmadlou S. Genetic evaluation of bone marrow-derived mesenchymal stem cells by a modified karyotyping method. Comp Clin Pathol 2015;24:1361-1366

12. Shaterzadeh-Yazdi H, Mehrabani D, Khodakaram-Tafti A, Dianatpour M, Zare S, Tamaddon A, Razeghian- Jahromi I. Osteogenic potential of subcutaneous adipose-derived stem cells in a rabbit model. Online J Vet Res 2015;19: 436-445

13. Mehrabani D, Rahmanifar F, Mellinejad M, Tamadon A, Dianatpour M, Zare S, Jahromi IR, Ghobadi F. Isolation, culture, characterization, and adipogenic differentiation of heifer endometrial mesenchymal stem cells. Comp Clin Pathol 2014;24:1159-1164

14. Mahdiyar P, Zare S, Robati R, Dianatpour M, Torabi K,
Tamadon A, Razeghian Jahromi I, Tamadon A, Mehrabani D. Isolation, culture, and characterization of human dental pulp mesenchymal stem cells. Int J Pediatr 2014;2:44

15. Lassalle B, Mouthon MA, Riou L, Barroca V, Coureuil M, Boussin F, Testart J, Allemand I, Fouchet P. Bone marrow-derived stem cells do not reconstitute spermatogenesis in vivo. Stem Cells 2008;26:1385-1386

16. Nayernia K, Lee JH, Drusenheimer N, Nolte J, Wulf G, Dressel R, Gromoll J, Engel W. Derivation of male germ cells from bone marrow stem cells. Lab Invest 2006;86:654663

17. Lue Y, Erkkila K, Liu PY, Ma K, Wang C, Hikim AS, Swerdloff RS. Fate of bone marrow stem cells transplanted into the testis: potential implication for men with testicular failure. Am J Pathol 2007;170:899-908

18. Cakici C, Buyrukcu B, Duruksu G, Haliloglu AH, Aksoy A, Isık A, Uludag O, Ustun H, Subası C, Karaoz E. Recovery of fertility in azoospermia rats after injection of adipose-tissue-derived mesenchymal stem cells: the sperm generation. Biomed Res Int 2013;2013:529589

19. Monsefi M, Fereydouni B, Rohani L, Talaei T. Mesenchymal stem cells repair germinal cells of seminiferous tubules of sterile rats. Iran J Reprod Med 2013;11:537-544

20. Gnecchi M, Melo LG. Bone marrow-derived mesenchymal stem cells: isolation, expansion, characterization, viral transduction, and production of conditioned medium. Methods Mol Biol 2009;482:281-294

21. Leatherman J. Stem cells supporting other stem cells. Front Genet 2013;4:257

22. Mansour A, Abou-Ezzi G, Sitnicka E, Jacobsen SE, Wakkach A, Blin-Wakkach C. Osteoclasts promote the formation of hematopoietic stem cell niches in the bone marrow. J Exp Med 2012;209:537-549

23. Panahi M, Keshavarz S, Rahmanifar F, Tamadon A, Mehrabani D, Karimaghai N, Sepehrimanesh M, Aqababa H. Busulfan induced azoospermia: stereological evaluation of testes in rat. Vet Res Forum 2015. [Epub ahead of print]

24. Easley CA 4th, Simerly CR, Schatten G. Stem cell therapeutic possibilities: future therapeutic options for malefactor and female-factor infertility? Reprod Biomed Online 2013;27:75-80

25. Bibber B, Sinha G, Lobba AR, Greco SJ, Rameshwar P. A review of stem cell translation and potential confounds by cancer stem cells. Stem Cells Int 2013;2013:241048

26. Aghamir SM, Salavati A, Yousefie R, Tootian Z, Ghazaleh N, Jamali M, Azimi P. Does bone marrow-derived mesenchymal stem cell transfusion prevent antisperm antibody production after traumatic testis rupture? Urology 2014;84: $82-86$

27. Mital P, Kaur G, Dufour JM. Immunoprotective sertoli cells: making allogeneic and xenogeneic transplantation feasible. Reproduction 2010;139:495-504

28. Zhu Y, Hu HL, Li P, Yang S, Zhang W, Ding H, Tian RH, Ning Y, Zhang LL, Guo XZ, Shi ZP, Li Z, He Z. Generation of male germ cells from induced pluripotent stem cells (iPS cells): an in vitro and in vivo study. Asian 


\section{J Androl 2012;14:574-579}

29. Van Saen D, Goossens E, De Block G, Tournaye H. Bone marrow stem cells transplanted to the testis of sterile mice do not differentiate into spermatogonial stem cells and have no protective effect on fertility. Fertil Steril 2009;91(4 Suppl):1549-1552

30. Drusenheimer N, Wulf G, Nolte J, Lee JH, Dev A, Dressel R, Gromoll J, Schmidtke J, Engel W, Nayernia K. Putative human male germ cells from bone marrow stem cells. Soc Reprod Fertil Suppl 2007;63:69-76

31. Zahkook SA, Atwa A, Shahat M, Mansour AM, Bakry S. Mesenchymal stem cells restore fertility in induced azoospermic rats following chemotherapy administration. J Reprod Infertil 2014;5:50-57

32. Sabbaghi MA, Bahrami AR, Feizzade B, Kalantar SM, Matin MM, Kalantari M, Aflatoonian A, Saeinasab M. Trial evaluation of bone marrow derived mesenchymal stem cells (MSCs) transplantation in revival of spermatogenesis in testicular torsion. Middle East Fertil Soc J 2012;17:243-249

33. Mehrabani D, Hassanshahi MA, Tamadon A, Zare S, Keshavarz S, Rahmanifar F, Dianatpour M, Khodabandeh Z, Jahromi I, Tanideh N, Ramzi M, Aqababa H, KuhiHoseinabadi O. Adipose tissue-derived mesenchymal stem cells repair germinal cells of seminiferous tubules of busulfan-induced azoospermic rats. J Hum Reprod Sci 2015; 8:103-110
34. Chen H, Tang QL, Wu XY, Xie LC, Lin LM, Ho GY, Ma L. Differentiation of human umbilical cord mesenchymal stem cells into germ-like cells in mouse seminiferous tubules. Mol Med Rep 2015;12:819-828

35. Berookhim BM, Schlegel PN. Azoospermia due to spermatogenic failure. Urol Clin North Am 2014;41:97-113

36. Suttorp M, Millot F. Treatment of pediatric chronic myeloid leukemia in the year 2010: use of tyrosine kinase inhibitors and stem-cell transplantation. Hematology Am Soc Hematol Educ Program 2010;2010:368-376

37. Bartelink IH, van Reij EM, Gerhardt CE, van Maarseveen EM, de Wildt A, Versluys B, Lindemans CA, Bierings MB, Boelens JJ. Fludarabine and exposure-targeted busulfan compares favorably with busulfan/cyclophosphamide-based regimens in pediatric hematopoietic cell transplantation: maintaining efficacy with less toxicity. Biol Blood Marrow Transplant 2014;20:345-353

38. Panahi M, Karimaghai N, Rahmanifar F, Tamadon A, Vahdati AA, Mehrabani D, Koohi-Hosseinabadi O, Sepehrimanesh $M$. Stereological evaluation of testes after the induction of infertility using busulfan in hamster. Comp Clin Pathol 2015;24:1051-1056

39. de Rooij DG, Vergouwen RP. The estimation of damage to testicular cell lineages. Prog Clin Biol Res 1991;372:467-480

40. Johnson AL, Howards SS. Intratubular hydrostatic pressure in testis and epididymis before and after long-term vasectomy in the guinea pig. Biol Reprod 1976;14:371-376 